\section{RELEASE OF $\alpha$-TOCOPHEROL FROM CHITOSAN/PECTIN POLYELECTROLYTE COMPLEX FILM INTO FATTY FOOD SIMULANT FOR THE DESIGN OF ANTIOXIDANT ACTIVE FOOD PACKAGE}

\author{
Aulia Ratri Hapsari, Roto, Dwi Siswanta*
}

Department of Chemistry, Faculty of Mathematics and Natural Sciences, Universitas Gadjah Mada, Sekip Utara Bls 21, Yogyakarta, Indonesia, 55281

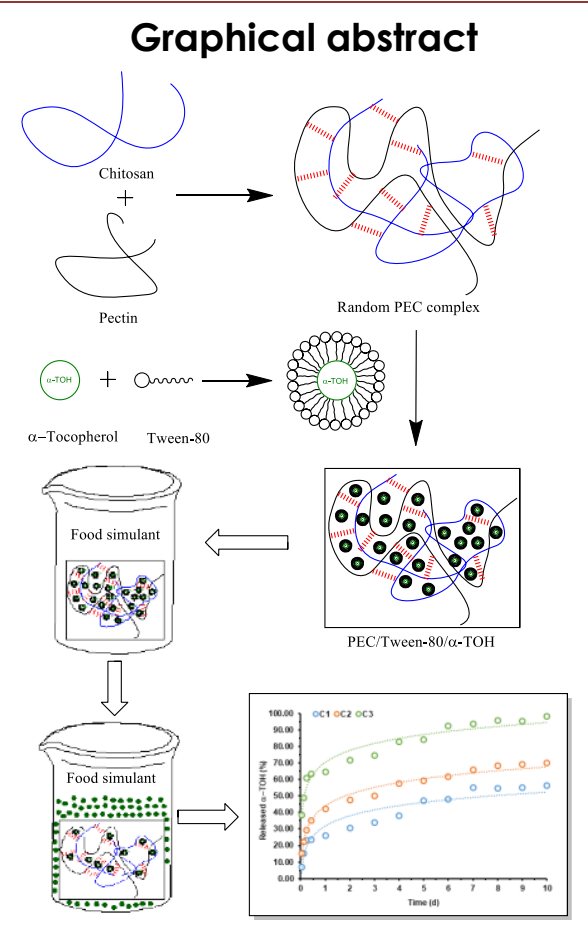

Article history

Received

21 June 2019

Received in revised form

5 December 2019

Accepted

16 January 2020

Published online

27 February 2020

*Corresponding author dsiswanta@ugm.ac.id

\begin{abstract}
Lipid oxidation is one of the leading causes of the decline in food product quality. However, it might be overcome with active antioxidant packaging technologies, which is based on the incorporation of antioxidants to the packaging material. In this study, the polyelectrolyte complex (PEC) from chitosan (CS) and pectin (PE) was used as a packaging material and $\alpha$-tocopherol $(\alpha-\mathrm{TOH})$ was used as an antioxidant to develop an antioxidant active packaging with the addition of Tween-80 to facilitate the incorporation of hydrophobic $\alpha-\mathrm{TOH}$ into hydrophilic PEC CS/PE solution. This research showed that the composition of PEC chitosan/pectin, the concentration of Tween-80, and the concentration of $\alpha-\mathrm{TOH}$ affected the releasing profile of $\alpha-\mathrm{TOH}$. The hydrophilicity of film increased with the increase of PE amount in PEC and the concentration of Tween-80. This improvement in the hydrophilicity also led to an increase in the release of $\alpha-\mathrm{TOH}$. The highest accumulative release of $\alpha-\mathrm{TOH}$ was achieved when using a film with the highest initial concentration of incorporated $\alpha-\mathrm{TOH}(\mathrm{C} 3)$, which was up to $98.49 \%$. The result of the performed DPPH assay showed that the complex films exhibited high antioxidant activity up to $90.60 \%$. The releasing profile of all films exhibited an initial burst effect followed by sustain release over $10 \mathrm{~d}$. Therefore, this film can be promising as an antioxidant active package.
\end{abstract}

Keywords: PEC chitosan/pectin, $\alpha$-tocopherol, release, antioxidant, active food package

\subsection{INTRODUCTION}

Lipid oxidation is one of the leading causes of the decline in food product quality. The oxidation of lipids in food products resulted in the development of offflavor, color, and flavor change. Nutritional losses due to degradation of polyunsaturated fatty acids (PUFA) and the formation of toxic aldehyde is also caused by oxidation of lipids in food products [1-3]. One method that can be conducted to reduce lipid oxidation is the addition of antioxidants directly to food products. Antioxidants are added to food in order to intercept and react with free radicals. The reaction between free radicals and antioxidants had a faster rate than the reaction between free radicals and lipid substrate. Therefore, food products can be protected from lipid oxidation [4].

The direct addition of antioxidants with a high initial dose into food products has a prooxidant effect, which will decrease its shelf life. Moreover, it is 
not efficient since the oxidation occurs at the surface of food [4-6]. Those limitations can be overcome with active antioxidant packaging technologies, which is based on the incorporation of antioxidants to the packaging material as a way to reduce oxidation in sensitive food products. This type of packaging can provide a gradual release of antioxidants from packaging material to food surface at the appropriate rate, so then lipid oxidation on the surface of food can be avoided [1], [7].

Research on active antioxidant packaging has been conducted progressively. Jongjareonrak et al. [2] reported that the incorporation of Butylated hydroxytolvene (BHT) into fish skin gelatin films exhibited excellent antioxidant activity indicated by the increase in di(phenyl)- $(2,4,6$ trinitrophenyl)iminoazanium (DPPH) radical scavenging with increasing storage time. However, the safety of the food due to the presence of a synthetic antioxidant is questioned. Recently, there has been growing interest in using natural antioxidants.

$\alpha$-tocopherol $(\alpha-\mathrm{TOH})$ is a natural antioxidant that is classified as substance recognized as safe for intended use in food. The use of $\alpha-\mathrm{TOH}$ as an antioxidant has been widely studied and shown good activity when evaluated through both in vitro and in vivo assay [5], [7-9].

The environmental impact of non-biodegradable plastic materials has encouraged researchers to develop biodegradable packaging materials. Chitosan (CS) is a natural polymer obtained by deacetylation of chitin and possess biocompatible, biodegradable, non-toxic, and good film-forming properties. Due to its unique properties, chitosan has been widely used for the manufacture of films. Incorporation of $\alpha$-TOH into CS-based film showed good radical scavenging activity and may also be used to protect foods from UV-light-induced degradation [3]. However, the application of CS as a film is limited due to its poor mechanical properties. One of the strategies that can be used to improve the mechanical properties of CS film is introduced by oppositely charged polyelectrolytes, i.e., polycation and polyanion, to form polyelectrolyte complex (PEC) [10], [11]. CS has amine groups, which are polycationic in acidic medium. Some polyanion has been studied in the formation of PEC with CS; one of them is pectin (PE). PE is a natural polysaccharide, which is non-toxic, biodegradable, and widely used in the food industry. Carboxyl groups of PE can interact with the protonated amine group of CS, leading to the formation of PEC [10], [11]. The formation of PEC between CS and PE proved in increasing the tensile strength up to 4-times higher compared to pure CS film. The improvement in tensile strength is due to the ionic interaction between CS and PE [10], [11].

In the present study, chitosan/pectin polyelectrolyte complex (PEC CS/PE) will be used as a packaging material and $\alpha-\mathrm{TOH}$ used as an antioxidant to develop an antioxidant active packaging. Since $\alpha-\mathrm{TOH}$ is a hydrophobic antioxidant, Tween-80 was added to facilitate the incorporation of $\alpha$-TOH into hydrophilic PEC CS/PE solution. The gradual release of $\alpha-\mathrm{TOH}$ from PEC CS/PE films was studied. Some factors that affected the release of $\alpha-\mathrm{TOH}$, including the composition of PEC CS/PE, the concentration of Tween-80, and the initial concentration of $\alpha-\mathrm{TOH}$ were studied. Antioxidant activity of prepared antioxidant active packaging was evaluated as well.

\subsection{METHODOLOGY}

\section{Preparation of Chitosan/Pectin Polyelectrolyte Complex Film}

Polyelectrolyte complex solutions with three different compositions were prepared by dissolving PE in various amounts in $4 \mathrm{~mL}$ of distilled water. Different amount of CS was then added into pectin solution with constant stirring for one hour. Afterward, $16 \mathrm{~mL}$ of $0.4 \mathrm{M}$ acetic acid was added and stirred until a homogenous PEC solution was obtained.

Table 1 Composition of chitosan (CS), pectin (PE), Tween-80 and $\alpha$-tocopherol $(\alpha-\mathrm{TOH})$ in $10 \mathrm{~mL}$ of film-forming solution

\begin{tabular}{ccccc}
\hline Film & CS $(\mathbf{m g})$ & PE $(\mathbf{m g})$ & Tween-80 $(\mathbf{m g})$ & $\alpha$-TOH $(\mathbf{m g})$ \\
\hline A1 & 45 & 5 & 20 & 10 \\
A2 & 40 & 10 & 20 & 10 \\
A3 & 35 & 15 & 20 & 10 \\
B1 & 40 & 10 & 10 & 10 \\
B2 & 40 & 10 & 20 & 10 \\
B3 & 40 & 10 & 40 & 10 \\
C1 & 40 & 10 & 40 & 5 \\
C2 & 40 & 10 & 40 & 10 \\
C3 & 40 & 10 & 40 & 20 \\
\hline
\end{tabular}

Film-forming solutions were prepared by incorporating $\alpha-\mathrm{TOH}$ and Tween-80 into a PEC solution to obtain a final concentration of $0.05,0.1$ and $0.2 \%(\mathrm{w} / \mathrm{v})$ for $\alpha-\mathrm{TOH}$ and $0.1,0.2$ and $0.4 \%$ $(\mathrm{w} / \mathrm{v})$ for Tween-80 (Table 1). The mixture was stirred for one hour at $25^{\circ} \mathrm{C}$. Ten milliliters of film-forming solutions were poured into a petri dish and dried in an oven at $70^{\circ} \mathrm{C}$. Afterward, $10 \mathrm{~mL}$ of $1 \mathrm{M} \mathrm{NaOH}$ was added to help remove the film from a petri dish. The film was washed with distilled water until neutral, then was air-dried until completely dried and stored for further analysis. The symbol and composition of the film used in this study are shown in Table 1.

\section{Characterization of Film}

The FT-IR spectra of films were determined with an FTIR Spectrometer (Shimadzu FT-IR Prestige 21), and the spectra were collected over the range of $400-4000$ $\mathrm{cm}^{-1}$. The tensile strength of films was measured by a Universal Test Machine (UTM) (Zwick/Roell Z05). In order to measure the water uptake capability of the 
prepared films, the dried weight ( $W_{\text {dry }}$ ) of the film and the weight of film after being soaked in $10 \mathrm{~mL}$ of distilled water for one hour ( $\left.\mathrm{W}_{\text {wet }}\right)$ were measured. The water uptake was then calculated using Eq. (1):

$$
\text { Water uptake }(\%)=\frac{\mathrm{W}_{\text {wet }}-\mathrm{W}_{\mathrm{dry}}}{\mathrm{W}_{\mathrm{dry}}} \times 100 \%
$$

\section{Release Study}

The amount of $\alpha-\mathrm{TOH}$ released from PEC CS/PE films in the fatty food simulant $(20 \mathrm{~mL})$ at $25^{\circ} \mathrm{C}$ was monitored as a function of time for $10 \mathrm{~d}$. The concentration of $\alpha-\mathrm{TOH}$ released was determined by UV-Vis spectrophotometry (GBC Cintra 2020 V4131) at $291.21 \mathrm{~nm}$.

\section{In Vitro Antioxidant Activity}

The antioxidant activity of prepared films was evaluated through the in vitro test of DPPH free radical according to the method by Quiñones et al. [12] with slight modification. In detail, $0.5 \mathrm{~mL}$ of $\alpha-\mathrm{TOH}$ released from PEC CS/PE film into ethanol $96 \%(\mathrm{v} / \mathrm{v})$ were mixed with $3.5 \mathrm{~mL}$ of $75 \mu \mathrm{M}$ DPPH in ethanol 96 $\%(\mathrm{v} / \mathrm{v})$. The control was obtained using $0.5 \mathrm{~mL}$ ethanol $96 \%(\mathrm{v} / \mathrm{v})$. The mixture solution was kept in the dark at room temperature for $30 \mathrm{~min}$, and the absorbance was then measured at $517 \mathrm{~nm}$. The radical scavenging activity (RSA) was calculated using Equation (2):

$$
\operatorname{RSA}(\%)=\left(1-\frac{A_{\text {sample }}}{A_{\text {control }}}\right) \times 100 \%
$$

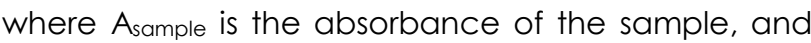
Acontrol is the absorbance of control.

\subsection{RESULTS AND DISCUSSION}

\section{Characterization of Film}

FT-IR analysis was performed to determine the characteristics of the compounds in the film as well as the changes in the molecular interaction among the compounds. FT-IR spectra of chitosan (CS), pectin (PE), and polyelectrolyte complex (PEC) can be seen in Figure 1. CS spectra showed an absorption band at $3449 \mathrm{~cm}^{-1}$, assigned to the overlapping stretching vibration of $-\mathrm{OH}$ and $-\mathrm{NH}$ groups. An absorption band at 2924 and $2886 \mathrm{~cm}^{-1}$ is associated with aliphatic $\mathrm{C}-\mathrm{H}$ stretching. The absorption band at 1088 and $1033 \mathrm{~cm}^{-1}$ can be attributed to $\mathrm{C}-\mathrm{O}-\mathrm{C}$ stretching, which is characteristic of the saccharide structure of CS [12], [13]. Characteristic absorption of CS appears at $1605 \mathrm{~cm}^{-1}$, which is associated with the overlapping of amide II and $\mathrm{N}-\mathrm{H}$ bending vibration. The absorption band at $1651 \mathrm{~cm}^{-1}$ corresponding to the $\mathrm{C}=\mathrm{O}$ stretching of the amide group of the acetylated units of CS [10], [11], [14], [15].
In the PE spectra, the absorption band at $1628 \mathrm{~cm}^{-1}$ is associated with stretching vibration of the carboxylate group $(\mathrm{C}=\mathrm{O})$ while the absorption band at $1751 \mathrm{~cm}^{-1}$ is assigned to the vibration of $\mathrm{C}=\mathrm{O}$ of the methyl ester group (COCH3) [10], [11], [14], [15]. Another absorption band in PE spectra appears at 3410 and $3325 \mathrm{~cm}^{-1}$, corresponding to the $\mathrm{O}-\mathrm{H}$ vibration. The absorption band at $2940 \mathrm{~cm}^{-1}$ is associated with aliphatic $\mathrm{C}-\mathrm{H}$ stretching. The absorption band at $1150 \mathrm{~cm}^{-1}$ can be attributed to anti-symmetric stretching of the C-O-C bridge while the band at $1018 \mathrm{~cm}^{-1}$ is related to skeletal vibration involving the $\mathrm{C}-\mathrm{O}-\mathrm{C}$ stretching, which is characteristic of saccharide structure of PE [10], [13].

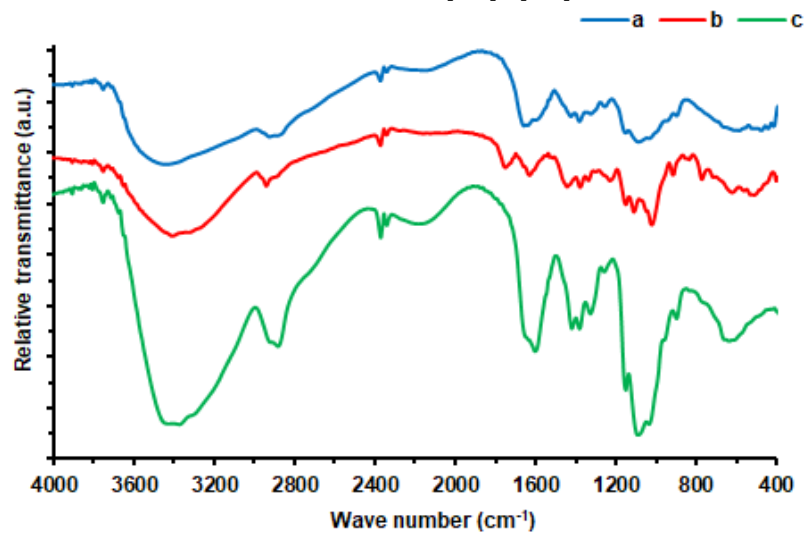

Figure 1 FT-IR spectra of CS (a), PE (b), and PEC CS/PE (c)

The characteristic absorption of CS at $1605 \mathrm{~cm}^{-1}$ shifted to $1597 \mathrm{~cm}^{-1}$ in the PEC spectra. It indicates a change in the environment of amine groups of CS through its interaction with PE [14]. The shift in carboxylate band of PE to $1597 \mathrm{~cm}^{-1}$ also indicates a changing environment of carboxylate groups of $P E$ due to its interaction with CS [16]. A strong intensity absorption band at $1597 \mathrm{~cm}^{-1}$ in PEC spectra indicates an ionic interaction occurred between ionized amine groups of CS $\left(-\mathrm{NH}_{3}{ }^{+}\right)$and ionized carboxylate groups $\left(-\mathrm{COO}^{-}\right)$of $\mathrm{PE}$, leading to the formation of a polyelectrolyte complex (PEC) [11], [15]. Moreover, the absorption band of $C=O$ bonds on both CS and PE were covered due to the high ionic interaction [1 11 ].

In this study, Tween-80 was added to help the incorporation of $\alpha$-TOH into hydrophilic PEC CS/PE solution. Figure 2. shows the FT-IR spectra of PEC, Tween-80, and PEC/Tween-80. The spectra of Tween80 were characterized by the presence of an absorption band at $3441 \mathrm{~cm}^{-1}$ due to the stretching vibration of $-\mathrm{OH}$ groups, a band at 2924 and 2862 $\mathrm{cm}^{-1}$ due to asymmetric and symmetric stretching for the methylene group $\left(-\mathrm{CH}_{2-}\right)$, a band at $1736 \mathrm{~cm}^{-1}$ due to stretching of $\mathrm{C}=\mathrm{O}$ groups that represented the ester group of Tween-80 and a band at $1636 \mathrm{~cm}^{-1}$ which is associated with $\mathrm{C}=\mathrm{C}$ absorption [17]. A new band appears in PEC/Tween-80 spectra at $2924 \mathrm{~cm}^{-1}$ is due to $\mathrm{C}-\mathrm{H}$ stretching vibration of a methylene group. It indicates an introduction of aliphatic chains from Tween-80 to PEC CS/PE. The broader stretching 
vibration of the $-\mathrm{OH}$ group at $3372 \mathrm{~cm}-1$ was observed, indicating an interaction between PEC and Tween-80. The PEC films with or without Tween-80 have the same FT-IR spectra, showing no significant interactions between PEC and Tween-80. Tween-80 merely entrapped in the PEC through weak electrostatic interactions and hydrophobic interactions [15], [18].

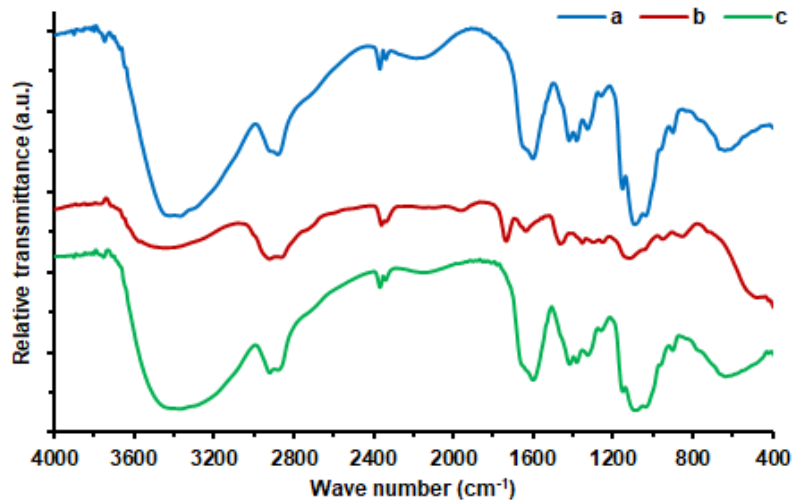

Figure 2 FT-IR spectra of PEC (a), Tween-80 (b), and PEC/Tween-80 (c)

FT-IR spectra of PEC/Tween-80, $\alpha-\mathrm{TOH}$ and $\mathrm{PEC} / \mathrm{Tw}$ een-80/ $\alpha$-TOH can be seen in Figure 3. $\alpha-\mathrm{TOH}$ was identified by the presence of an absorption band at $3480 \mathrm{~cm}^{-1}$, assigned to the stretching vibration of $-\mathrm{OH}$ group, bands at 2924 and $2855 \mathrm{~cm}^{-1}$ due to asymmetric and symmetric stretching for methylene group $\left(-\mathrm{CH}_{2-}\right)$, a band at $1373 \mathrm{~cm}^{-1}$ due to asymmetric stretching vibration of methyl groups ($\mathrm{CH}_{3}$ ) and a band at $1636 \mathrm{~cm}^{-1}$ which is associated with $\mathrm{C}=\mathrm{C}$ absorption of phenyl group [3], [5], [19]. Strong intensity at $2924 \mathrm{~cm}^{-1}$ and shifted absorption band of a methyl group to $1381 \mathrm{~cm}^{-1}$ after incorporation of $\alpha-\mathrm{TOH}$ into PEC/Tween-80, indicated the introduction of aliphatic chain. The shift in $-\mathrm{OH}$ band of PEC/Tween-80 to $3372 \mathrm{~cm}^{-1}$ with stronger intensity indicates hydrogen bonds formed between $\alpha-\mathrm{TOH}$ and PEC/Tween-80 system. The hydrogen bonds could be formed between amine groups of $\mathrm{CS}$ in PEC/Tween-80 and hydroxyl groups of $\alpha$-TOH [5], [19].

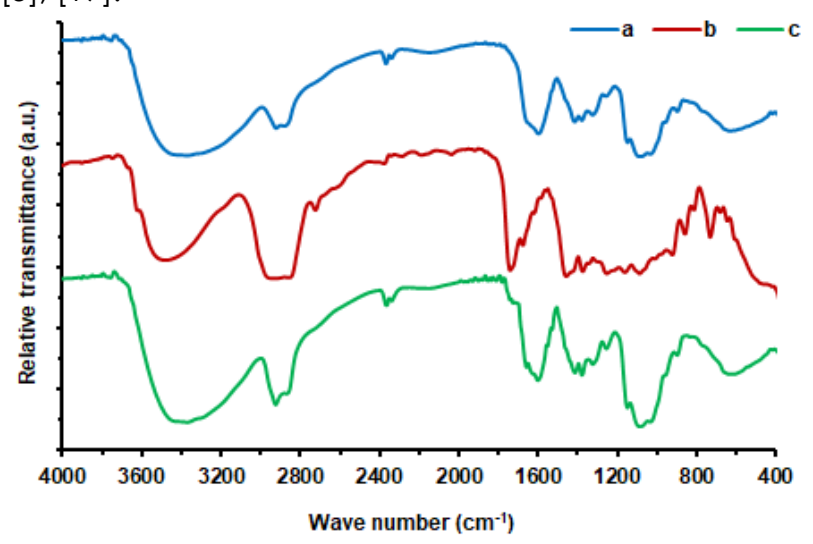

Figure 3 FT-IR spectra of PEC/Tween-80 (a), $\alpha-\mathrm{TOH}(\mathrm{b})$, and $\mathrm{PEC} / \mathrm{Tw}$ ween-80/ $\alpha-\mathrm{TOH}$ (c)
The interactions between PEC CS/PE, Tween-80, and $\alpha-\mathrm{TOH}$ in the film can be estimated from the interpretation of FTIR data and are illustrated in Figure 4. The antioxidant $\alpha$-TOH will be entrapped into PEC CS/PE through incorporation into the micelle core of Tween-80. The presence of Tween-80 allows a hydrophobic antioxidant, $\alpha-\mathrm{TOH}$, that is normally insoluble, to dissolve in the hydrophilic PEC CS/PE solution. The hydrophobic tails of Tween-80 would assemble into the oil-like core, leads to the formation micelle (Oil-in-Water, O/W micelle). The interaction between $\alpha-\mathrm{TOH}$ with Tween-80 occurs through hydrophobic interactions between the hydrophobic tail of Tween-80 with the hydrophobic chain of $\alpha-\mathrm{TOH}$. In PEC CS/PE solution, the hydrophilic heads of Tween-80 would be in contact with the hydrophilic PEC CS/PE solution through the electrostatic interaction of the dipole-ion so that the micelles containing hydrophobic $\alpha-\mathrm{TOH}$ will dissolve in the hydrophilic PEC CS/PE solution.

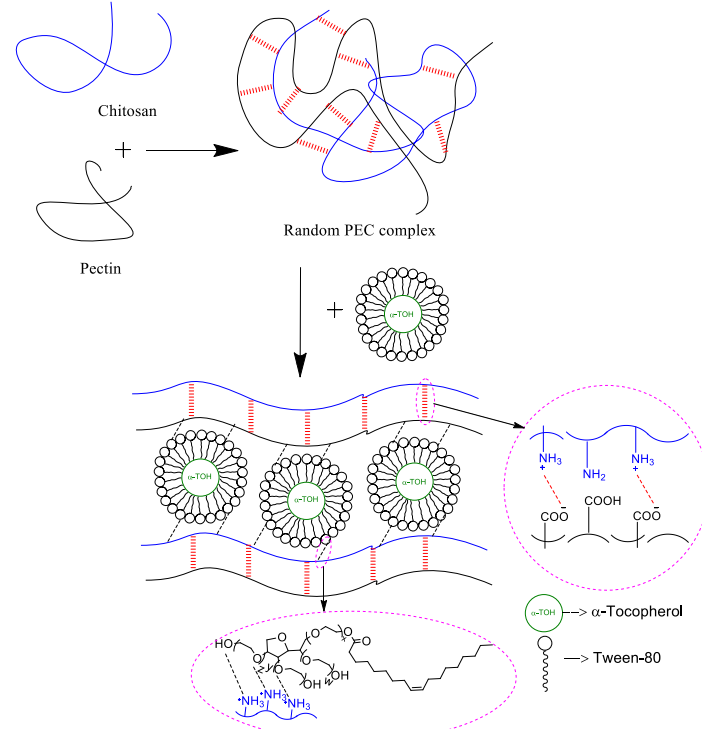

Figure 4 The proposed interactions between PEC CS/PE, Tween-80 and $\alpha-\mathrm{TOH}$ in the prepared film

The tensile strength of CS, PEC, PEC/Tween, and $\mathrm{PEC} / \mathrm{Tw}$ een-80/ $\alpha-\mathrm{TOH}$ are given in Table 2 . From the results, it can be observed that PEC film (entry 2) exhibits higher tensile strength than CS films (entry 1). It proves that the formation of PEC between CS and $P E$ could increase the tensile strength. This enhancement may be attributed to the ionic interaction that occurred between CS and PE [11], [20], [21]. The addition of Tween-80 (entry 3) does not give any significant change in tensile strength. The decline in tensile strength value may be attributed to the plasticizing effect of Tween-80. The plasticizing effect of Tween-80 is increasing the free volume between polymer chains and its structure becomes fragile [17], [22]. Incorporation of $\alpha-\mathrm{TOH}$ significantly decreased the tensile strength of the PEC/Tween-80 film (entry 4). This result shows that the addition of hydrophobic compounds will affect the interaction 
between CS and PE in PEC. Incorporation of hydrophobic antioxidant, $\alpha-\mathrm{TOH}$, would increase the spacing between polymer chain in PEC, which would reduce the ionic interaction between CS and PE. The reduction of ionic interaction induced the structural discontinuities in the films [2], [3], [8].

Table 2 The tensile strength of chitosan, PEC, PEC/Tween, and PEC/Tween- $80 / \alpha-\mathrm{TOH}$

\begin{tabular}{clc}
\hline Entry & \multicolumn{1}{c}{ Film } & Tensile strength $(\mathbf{M P a})$ \\
\hline 1 & CS & 5.66 \\
2 & PEC & 35.45 \\
3 & PEC/Tween-80 & 34.92 \\
4 & PEC/Tween $80 / \alpha-\mathrm{TOH}$ & 16.64 \\
\hline
\end{tabular}

\section{Release Study}

The principal mechanism of an antioxidant active package is through the release of the antioxidant in the food product that is protected. Hydrophobic antioxidant would seem to be more suitable for foods with high lipid and vice versa. Since $\alpha-\mathrm{TOH}$ is antioxidant with hydrophobic characteristic, ethanol $96 \%(\mathrm{v} / \mathrm{v})$ was used to mimic fatty foodstuff. The concentration of released $\alpha-\mathrm{TOH}$ was quantified by aliquots at $25^{\circ} \mathrm{C}$ during $10 \mathrm{~d}$. As a result, the release profile was similar for all films, which exhibited an initial burst effect followed by sustained release over $10 \mathrm{~d}$.

Figure 5. Shows the effect of PEC chitosan/pectin composition to the release of $\alpha-\mathrm{TOH}$, which was found that the release depends on the composition of CS/PE. The increase of PE content in PEC leads to an increase of the accumulative release of $\alpha-\mathrm{TOH}$. The increase of accumulative released $\alpha-\mathrm{TOH}$ may be attributed to the improvement of hydrophilicity of film. The increase of PE content in PEC leads to an increase in water uptake capability (Table 3), which might also indicate the increase of hydrophilicity of films [1 11$]$.

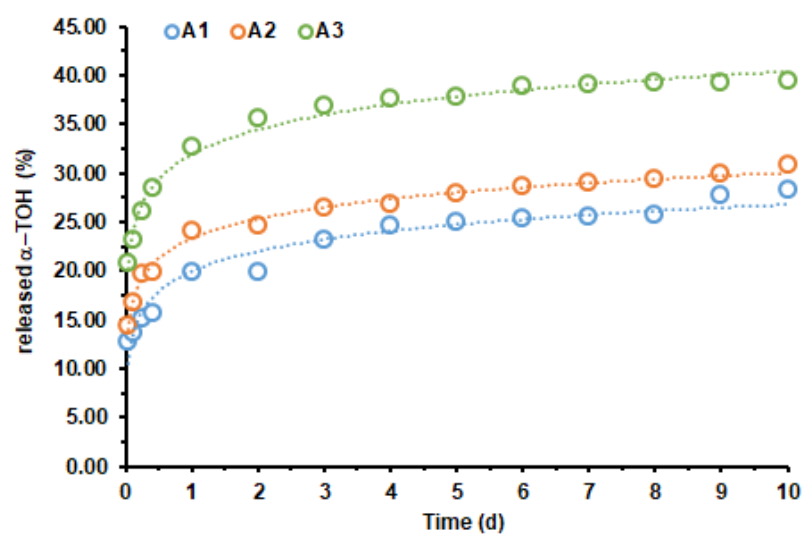

Figure 5 Effect of PEC CS/PE composition to the release of $\alpha$ TOH. Composition of PEC CS/PE 9:1 (A1), 8:2 (A2), and 7:3 (A3)
Table 3 Water uptake value of films

\begin{tabular}{cccccc}
\hline Film & $\begin{array}{c}\text { CS } \\
(\mathbf{m g})\end{array}$ & $\begin{array}{c}\text { PE } \\
(\mathbf{m g})\end{array}$ & $\begin{array}{c}\text { Tween- } \\
\mathbf{8 0}(\mathbf{m g})\end{array}$ & $\begin{array}{c}\boldsymbol{\alpha}-\mathrm{TOH} \\
(\mathbf{m g})\end{array}$ & $\begin{array}{c}\text { Water } \\
\text { Uptake }(\mathbf{\%})\end{array}$ \\
\hline A1 & 45 & $\mathbf{5}$ & 20 & 10 & 130.48 \\
$\mathrm{~A} 2$ & 40 & $\mathbf{1 0}$ & 20 & 10 & 146.46 \\
$\mathrm{~A} 3$ & 35 & $\mathbf{1 5}$ & 20 & 10 & 163.91 \\
$\mathrm{~B} 1$ & 40 & 10 & $\mathbf{1 0}$ & 10 & 128.57 \\
$\mathrm{~B} 2$ & 40 & 10 & $\mathbf{2 0}$ & 10 & 146.46 \\
B3 & 40 & 10 & $\mathbf{4 0}$ & 10 & 160.78 \\
C1 & 40 & 10 & 40 & $\mathbf{5}$ & 157.21 \\
C2 & 40 & 10 & 40 & $\mathbf{1 0}$ & 160.78 \\
C3 & 40 & 10 & 40 & $\mathbf{2 0}$ & 157.22 \\
\hline
\end{tabular}

The release of $\alpha-\mathrm{TOH}$ involves two processes: First, ethanol $96 \%(v / v)$ penetrates the pores to dissolve $\alpha$ $\mathrm{TOH}$. Second, the dissolved $\alpha-\mathrm{TOH}$ diffuse out of the films. In this present work, ethanol $96 \%$ (v/v) penetrates the films faster due to the high hydrophilicity of films producing the increase in a release [5].

Figure 6 presented the releasing profile of $\alpha-\mathrm{TOH}$ as a function of the concentration of non-ionic surfactant, Tween-80. The increase of Tween-80 concentration promoted an increase in the accumulative release of $\alpha-\mathrm{TOH}$. This could also be mainly attributed to the increase of hydrophilicity of films with the increasing concentration of Tween-80.

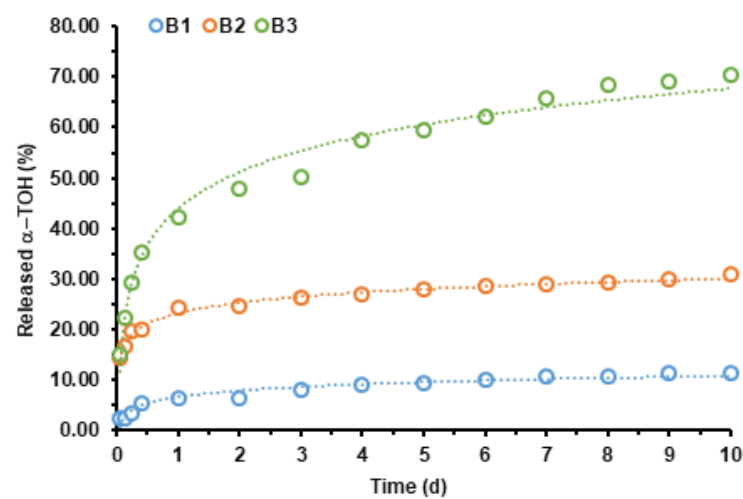

Figure 6 Effect of concentration of Tween-80 to the release of $\alpha-\mathrm{TOH}$. Concentration of Tween-80 $0.1 \%$ (w/v) (B1), $0.2 \%$ $(\mathrm{w} / \mathrm{v})(\mathrm{B} 2)$, and $0.4 \%(\mathrm{w} / \mathrm{v})(\mathrm{B} 3)$

Tween-80 is a non-ionic surfactant having a Hydrophilic-Lipophilic Balance (HLB) value of 15 , making Tween-80 hydrophilic surfactant. The increasing concentration of Tween-80 leads to an increase in water uptake capability (Table 3), which might also lead to increased hydrophilicity of films [11]. This improvement in hydrophilicity producing an increase in the release of $\alpha-\mathrm{TOH}$ [5]. 


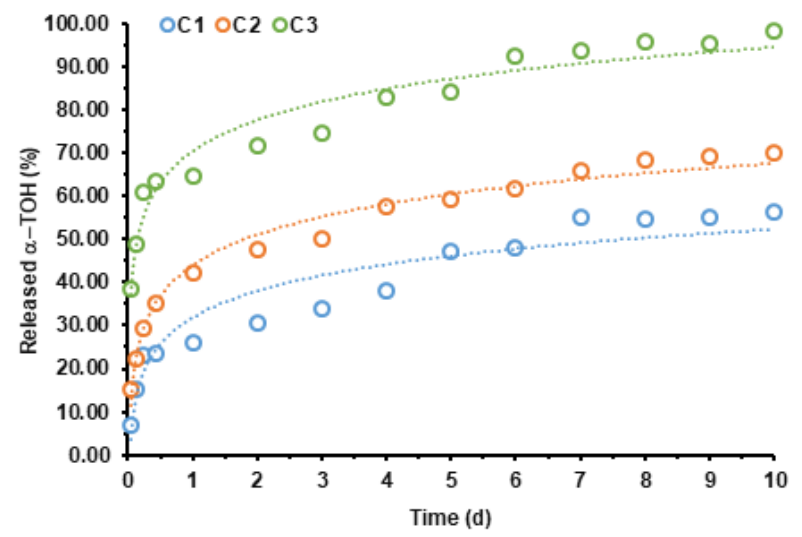

Figure 7 Effect of concentration of $\alpha-\mathrm{TOH}$ to the release of $\alpha-\mathrm{TOH}$. Incorporation concentration of $\alpha-\mathrm{TOH} 0.05 \%(\mathrm{w} / \mathrm{v})$ $(\mathrm{C} 1), 0.1 \%(\mathrm{w} / \mathrm{v})(\mathrm{C} 2)$, and $0.2 \%(\mathrm{w} / \mathrm{v})(\mathrm{C} 3)$

Figure 7 presented the release profile of $\alpha-\mathrm{TOH}$ as a function of the initial concentration of incorporated $\alpha-\mathrm{TOH}$. The increase of initial concentration of incorporated $\alpha-\mathrm{TOH}$ also promoted an increase in the release of $\alpha-\mathrm{TOH}$. However, the water uptake capability of three films with different $\alpha-\mathrm{TOH}$ concentration ( $\mathrm{C} 1, \mathrm{C} 2$, and $\mathrm{C} 3$ ) was similar (Table 4), indicating the profile release of $\alpha-\mathrm{TOH}$ from these films were not affected by its hydrophilicity. The plasticizing effect of $\alpha-\mathrm{TOH}$ may be another factor that increases the accumulative release of $\alpha-\mathrm{TOH}$. The addition of the hydrophobic $\alpha-\mathrm{TOH}$ will affect the interaction between chitosan and pectin in PEC by increasing space between polymer chain. Moreover, it would also increase the free volume between the polymer chain and $\alpha-\mathrm{TOH}$ would be dissolved rapidly out of pores [3], [5], [6], [22].

\section{In Vitro Antioxidant Activity}

Antioxidant activity detected by DPPH assay was investigated to verify the effectiveness of $\alpha-\mathrm{TOH}$ released into fatty food simulant. DPPH assay measures the ability of antioxidants for free radicals trapping by donating hydrogen atoms or electrons, producing, in consequence, the bleaching of the colored radical DPPH solutions. The antioxidant activity of the film is then indicated by the Radical Scavenging Activity (RSA) value. The result was presented in Figure 8. The longer time of release will increase RSA value as a result of an increase of $\alpha$ $\mathrm{TOH}$ from all types of films. Higher $\alpha$-TOH released meant high radical scavenging activity [5], [23]. Moreover, the effectiveness of $\alpha-\mathrm{TOH}$ is determined by its concentration so that the different initial concentrations of incorporated $\alpha-\mathrm{TOH}$ exhibits different antioxidant activity [5]. The C3 film, which has the highest amount of incorporated $\alpha-\mathrm{TOH}$, released the highest amount of $\alpha-\mathrm{TOH}$ and exhibited the highest antioxidant activity (RSA) up to $90.60 \%$.

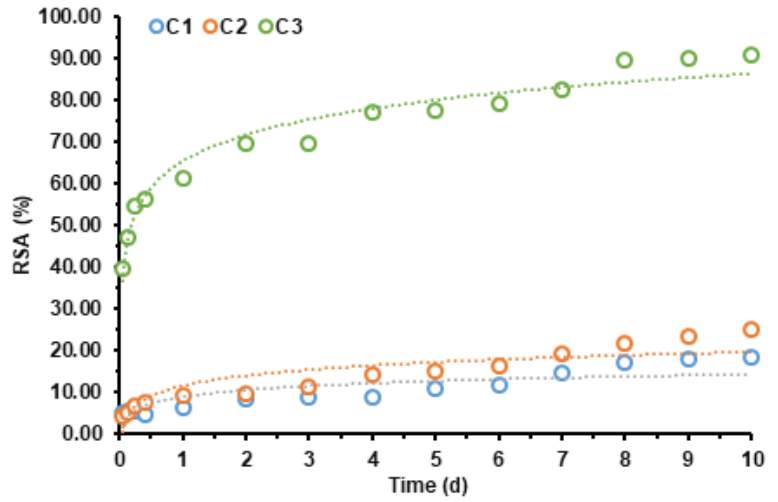

Figure 8 Effect of $\alpha-\mathrm{TOH}$ released to the antioxidant activity (RSA). Concentration of $\alpha-\mathrm{TOH}$ loaded $0.05 \%(\mathrm{w} / \mathrm{v})(\mathrm{C} 1)$, $0.1 \%(\mathrm{w} / \mathrm{v})(\mathrm{C} 2)$ and $0.2 \%(\mathrm{w} / \mathrm{v})(\mathrm{C} 3)$

\subsection{CONCLUSION}

In this study, the hydrophobic antioxidant $\alpha-\mathrm{TOH}$ was successfully incorporated into hydrophilic PEC CS/PE by adding non-ionic surfactant Tween-80. This research showed that the composition of PEC CS/PE, the concentration of Tween-80, and the concentration of $\alpha-\mathrm{TOH}$ affected on releasing profile of $\alpha-\mathrm{TOH}$. The hydrophilicity of film increased with the increase of pectin content in PEC and concentration of Tween-80, leading to the increased of the accumulative release of $\alpha-\mathrm{TOH}$. The increase of incorporated $\alpha-\mathrm{TOH}$ concentration also promoted increasing in the release of $\alpha$-TOH due to its plasticizer effect. The result of the performed DPPH assay showed that the complex films exhibited high antioxidant activity up to $90.60 \%$. The releasing profile of all films exhibited an initial burst effect followed by sustain release over $10 \mathrm{~d}$. Therefore, this film can be promising as an antioxidant active package.

\section{Acknowledgement}

The authors are grateful to the Indonesian Directorate General of Higher Education (DIKTI), Ministry of Research, Technology and Higher Education, the Republic of Indonesia for the financial support through a scholarship program, namely Beasiswa Pendidikan Pascasarjana Dalam Negeri 2013.

\section{References}

[1] Gómez-Estaca, J., López-de-Dicastillo, C., HernándezMuñoz, P., Catalá, R., and Gavara, R. 2014, Advances in Antioxidant Active Food Packaging. Trends Food Sci. Technol. 35: 42-51.

[2] Jongjareonrak, A., Benjakul, S., Visessanguan, W., and Tanaka, M. 2008. Antioxidative Activity and Properties of Fish Skin Gelatin Films Incorporated with BHT and atocopherol. Food Hydrocoll. 22: 449-458. 
[3] Martins, J. T., Cerqueira, M. A., and Vicente, A. A. 2012. Influence of a-tocopherol on Physicochemical Properties of Chitosan-based Films. Food Hydrocoll. 27: 220-227.

[4] López de Dicastillo, C., Castro-López, M. D. M., LópezVilariño, J. M., and González-Rodríguez, M. V. 2013. Immobilization of Green Tea Extract on Polypropylene Films to Control the Antioxidant Activity in Food Packaging. Food Res. Int. 53: 522-528. Available at: http://dx.doi.org/10.1016/j.foodres.2013.05.022.

[5] Gargiulo, N., Attianese, I., Buonocore, G. G., Caputo, D. Lavorgna, M., Mensitieri, G., and Lavorgna, M. 2013. $\alpha$ Tocopherol Release from Active Polymer Films Loaded with Functionalized SBA-15 Mesoporous Silica. Microporous Mesoporous Mater. 167: 10-15. Available at: http://dx.doi.org/10.1016/j.micromeso.2012.07.037.

[6] Graciano-verdugo, A.Z., Soto-valdez, H., Peralta, E., Cruzzárate, P., Islas-rubio, A.R., Sánchez-valdes, S., Sánchezescalante, A., and González-méndez, N. 2010, Migration of a-tocopherol from LDPE Films to Corn Oil and Its Effect on the Oxidative Stability. Food Res. Int. 43: 1073-1078. Available http://dx.doi.org/10.1016/j.foodres.2010.01.019.

[7] Marcos, B., Sárraga, C., Castellari, M., Kappen, F., Schennink, G., and Arnau, J. 2014. Development of Biodegradable Films with Antioxidant Properties Based on Polyesters Containing a-tocopherol and Olive Leaf Extract for Food Packaging Applications. Food Packag. Shelf Life 1. 140-150. Available at: http://www.sciencedirect.com/science/article/pii/S22142 89414000350.

[8] Noronha, C. M., De Carvalho, S. M., Lino, R. C., and Barreto, P. L. M. 2014, Characterization Of Antioxidant Methylcellulose Film Incorporated with $\alpha$-tocopherol Nanocapsules. Food Chem. 159: 529-535. Available at: http://dx.doi.org/10.1016/j.foodchem.2014.02.159.

[9] Manzanarez-López, F., Soto-Valdez, H., Auras, R., and Peralta, E. 2011 . Release of a-Tocopherol from Poly(lactic acid) Films, and Its Effect on the Oxidative Stability of Soybean Oil. J. Food Eng. 104: 508-517.

[10] Coimbra, P., Ferreira, P., Sousa, H. C. De, Batista, P., Rodrigues, M. A., Correia, I. J., and Gil, M. H. 2011. Preparation and Chemical and Biological Characterization of a Pectin/Chitosan Polyelectrolyte Complex Scaffold for Possible Bone Tissue Engineering Applications. Int. J. Biol. Macromol. 48: 112-118. Available at: http://dx.doi.org/10.1016/j.ijbiomac.2010.10.006.

[11] Chen, P. H., Kuo, T. Y., Kuo, J. Y., Tseng, Y. P., Wang, D. M., Lai, J. Y., and Hsieh, H. J. 2010, Novel Chitosan-pectin Composite Membranes with Enhanced Strength, Hydrophilicity and Controllable Disintegration. Carbohydr. Polym. 82: 1236-1242. Available at: http://dx.doi.org/10.1016/j.carbpol.2010.06.057.

[12] Quiñones, J. P., Gothelf, K. V., Kjems, J., Yang, C., Caballero, A. M. H., Schmidt, C., and Covas, C. P. 2013 Self-assembled Nanoparticles of Modified-chitosan Conjugates for the Sustained Release of dl-a-tocopherol, Carbohydr. Polym. 92: 856-864.
[13] Bernabé, P., Peniche, C., Guaymas, C. U., Varadero, C., $\mathrm{Km}$, N., and Postal, A. 2005, Swelling Behavior of Chitosan/Pectin Polyelectrolyte Complex Membranes: Effect of Thermal Cross-linking. Polym. Bull. 55: 367-375.

[14] Bigucci, F., Luppi, B., Cerchiara, T., Sorrenti, M., Bettinetti, G., Rodriguez, L., and Zecchi, V. 2008. Chitosan/pectin Polyelectrolyte Complexes: Selection of Suitable Preparative Conditions for Colon-specific Delivery of Vancomycin. Eur. J. Pharm. Sci. 35: 435-441.

[15] Maciel, V. B. V, Yoshida, C. M. P., and Franco, T. T. 2015. Chitosan/pectin Polyelectrolyte Complex as a pH Indicator. Carbohydr. Polym. 132: 537-45. Available at: http://www.sciencedirect.com/science/article/pii/S01448 61715005548 [Accessed August 14, 2015].

[16] Souza, R. R. De, Carvalho, I. X. De, Trevisan, M. T. S., Ricardo, M. P. S., Feitosa, J. P. A., and Paula, R. C. M. De 2009. Chitosan-coated Pectin Beads: Characterization and In Vitro Release of Mangiferin. Food Hydrocoll. 23: 2278-2286.

[17] Brandelero, R. P. H., Grossmann, M. V., and Yamashita, F. 2012. Films of Starch and Poly (butylene adipate coterephthalate) Added of Soybean Oil (SO) and Tween 80. Carbohydr. Polym. 90: 1452-1460. Available at: http://dx.doi.org/10.1016/j.carbpol.2012.07.015.

[18] Martínez-Camacho, A. P., Cortez-Rocha, M. O., EzquerraBraver, J. M., Graciano-Verdugo, A. Z., Rodriguez-Félix, F., Castillo-Ortega, M. M., Yépiz-Gómez, M. S., and Plascencia-Jatomea, M. 2010, Chitosan Composite Films: Thermal, Structural, Mechanical and Antifungal Properties. Carbohydr. Polym. 82: 305-315

[19] Luo, Y., Zhang, B., Whent, M., YU, L. L., and Wang, Q. 2011. Preparation and Characterization of Zein/Chitosan Complex for Encapsulation of $\alpha$-tocopherol, and Its In Vitro Controlled Release Study. Colloids Surfaces B Biointerfaces. 85: 145-152. Available at: http://dx.doi.org/10.1016/j.colsurfb.201 1.02.020.

[20] Zhu, M., Qian, J., Zhao, Q., An, Q., Song, Y., and Zheng, Q. 2011. Polyelectrolyte Complex (PEC) Modified by Poly (Vinyl Alcohol) and Their Blend Membranes for Pervaporation Dehydration. J. Memb. Sci. 378: 233-242. Available http://dx.doi.org/10.1016/j.memsci.2011.05.007.

[21] Smitha, B., Sridhar, S., and Khan, A. A. 2005. ChitosanSodium Alginate Polyion Complexes as Fuel Cell Membranes. Eur. Polym. J. 41: 1859-1866.

[22] Brandelero, R. P. H. Yamashita, F. Victória, M. and Grossmann, E. 2010. The Effect of Surfactant Tween 80 on the Hydrophilicity, Water Vapor Permeation, and the Mechanical Properties of Cassava Starch and Poly (Butylene adipate-co-terephthalate) (PBAT) Blend Films, Carbohydr. Polym. 82: 1102-1109. Available at: http://dx.doi.org/10.1016/j.carbpol.2010.06.034.

[23] López De Dicastillo, C., Ares Pernas, A., Castro López, M. D. M., López Vilariño, J. M., and González Rodríguez, M. V. 2013. Enhancing The Release of the Antioxidant Tocopherol from Polypropylene Films by Incorporating the Natural Plasticizers Lecithin, Olive Oil, or Sunflower Oil. J. Agric. Food Chem. 61: 11848-11857. 